\title{
A Study of the Effect of Sound Therapy in People with Mild Tinnitus
}

\author{
YeonWoo Sim ${ }^{1}$, TaeRim Lee ${ }^{1}$, In-Ki Jin ${ }^{2}$ \\ ${ }^{1}$ Department of Speech Pathology and Audiology, Graduate School, Hallym University, Chuncheon, Korea \\ ${ }^{2}$ Division of Speech Pathology and Audiology, Research Institute of Audiology and Speech Pathology, College of Natural Sciences, Hallym University, \\ Chuncheon, Korea
}

Received: July 28, 2021

Revised: October 18, 2021

Accepted: October 18, 2021

Correspondence:

In-Ki Jin, PhD

Division of Speech Pathology and

Audiology, Research Institute of

Audiology and Speech Pathology,

College of Natural Sciences, Hallym

University, 1 Hallimdaehak-gil,

Chuncheon 24252, Korea

Tel: +82-33-248-2221

Fax: +82-33-256-3420

E-mail: inkijin@hallym.ac.kr
Purpose: Tinnitus refers to the maladaptive perception of sound in the absence of external sounds. Sound therapy is a representative rehabilitation option that has been used to relieve the adverse effects of tinnitus. It helps to reduce the discomfort caused by tinnitus by providing various external background noises to those suffering from tinnitus. The purpose of this study was to identify the effects of sound therapy on tinnitus relief in people with mild tinnitus. Methods: Twelve participants with mild tinnitus participated in this study. Sound therapy was performed for 3 months using a customized mobile phone application. Broadband noise was used as the sound therapy stimulus. The level of stimulus was set to the level of the mixing point. The Korean version of the Tinnitus Primary Function Questionnaire (K-TPFQ) score, Visual Analogue Scale (VAS) score, and tinnitus loudness level were recorded as outcome measurements at baseline and 3 months. Results: There were no significant differences in the K-TPFQ and VAS scores and tinnitus loudness level between the baseline and 3-month follow-up session. Conclusion: The results of this study showed that sound therapy alone for 3 months does not provide significant tinnitus relief in participants with mild tinnitus. Therefore, considering only sound therapy for rehabilitation in people with mild tinnitus might not be ideal for providing relief.

Key Words: Sound therapy, Tinnitus, Mild tinnitus, Sound therapy application.

\section{INTRODUCTION}

이명은 외부에 소리가 존재하지 않음에도 불구하고 비정상적 으로 소리를 인지하는 현상을 의미한다(Jastreboff, 1990). 성 인 인구의 약 3 분의 1 은 살면서 한 번은 이명을 경험하며, 그중 10 15\%는 의학적 평가가 필요할 정도로 지속적인 이명을 가지 고 있다고 보고하고 있다(Heller, 2003). 심각한 이명은 삶의 질 에도 영향을 미칠 수 있는데 종종 우울증, 불안, 수면장애, 집중 력 저하와 같은 심리적인 문제를 동반한다(Andersson, 2002).

소리치료는 이명으로 인한 악영향을 완화시키기 위해 사용 되어 온 대표적인 재활법으로, 다양한 외부 배경소음을 대상자 에게 제공함으로써 이명으로 인한 불편함을 감소시키는 데 도 움을 준다(Tyler, 2006). Henry et al.(2006)은 중고도 이상 의 이명을 가진 대상자를 모집하여 무작위로 이명차폐(tinnitus

(c) This is an Open Access article distributed under the terms of the Creative Commons Attribution Non-Commercial License (https://creativecommons.org/ licenses/by-nc/4.0) which permits unrestricted non-commercial use, distribution, and reproduction in any medium, provided the original work is properly cited. masking), 이명재훈련치료(tinnitus retraining therapy) 그 룹으로 나누고, 이명장애척도(Tinnitus Handicap Inventory), 이명장애설문지(Tinnitus Handicap Questionnaire) 및 이 명심각도지수(Tinnitus Severity Index) 점수의 평균에 따라 대상자들의 이명 심각도를 '중도(moderate)', '고도(big)', '심도 (very big)'로 나누어 18 개월 동안 소리치료를 실시하였다. 연구 결과, '중도' 그룹의 경우 평균 효과 크기(effect size)는 이명차 폐 그룹에서 0.35 , 이명재훈련치료 그룹에서 0.49 였다. '고도' 그 룹의 효과 크기는 이명차폐 그룹에서 0.63 , 이명재훈련치료 그 룹에서 0.85 였으며, '심도' 그룹은 이명차폐 그룹에서 0.64 , 이명 재훈련치료 그룹에서 1.08 이었다. 이러한 결과는 이명차폐와 이 명재훈련치료 그룹 모두 소리치료를 사용한 이명 재활이 효과적 이었음을 시사한다. 효과 크기(Cohen's D)는 두 그룹의 평균 차 이를 합동 표준편차(pooled standard deviation [SD])로 나 누어 표준화하는 것을 의미한다. 이 값은 0.2 이상은 작은 효과 크기(small effect size), 0.5 이상은 보통 효과 크기(medium 
effect size), 0.8 이상은 큰 효과 크기(large effect size)로 해 석한다(Cohen, 2013). Jin et al.(2021a)은 중도 이상의 이명 대 상자를 모집하여 광대역잡음(broadband noise)과 노치형잡음 (notched noise) 그룹으로 나누어 12개월 동안 소리치료를 실 시하였다. 연구 결과, 광대역잡음 그룹의 경우 한국어버전 이명 주요기능설문지(Korean version of the Tinnitus Primary Function Questionnaire; Shin et al., 2019) 점수가 평균 47.88점에서 12.57점으로 35.31점 감소하였고, 노치형잡음 그 룹의 경우 54.41점에서 22.31점으로 32.10점 감소하여 소리치 료를 사용한 이명 중재의 유의미한 효과를 보여주었다. Tyler et al.(2020)은 중도 이상의 이명을 가진 대상자를 모집하여 6주 동안 소리치료를 실시하였다. 연구 결과, 대상자의 15 명 중 5명 (33\%)이 이명주요기능설문지(Tinnitus Primary Function Questionnaire; Tyler et al., 2014) 점수에서 13점 이상의 유 의미한 감소를 보였다. 이처럼 소리치료는 다수의 연구를 통하여 이명에 대한 개선 효과를 보여주었다.

Henry et al.(2006), Jin et al.(2021a) 및 Tyler et al.(2020) 의 연구 결과들을 통하여 만성 이명 대상자들에게 있어서 소 리치료가 효과적인 이명 중재법임을 확인할 수 있었지만, 위 연 구들의 참여자들은 대부분 중도 이상의 이명을 호소한 대상자 들이었다. 예를 들어, Henry et al.(2006)은 대상자 그룹을 중 도 이명 이상의 대상자로 한정하여 연구를 진행하였고, Tyler et al.(2020)의 경우에도 연구 참여자의 기준을 초기 이명설문 지 점수 30점 이상으로 제한하여 30점 미만의 경도 이명 대상 자들을 제외하였다. 이명의 정도를 나누는 명확한 기준이 존재 하지는 않지만 소리치료의 효과를 보여주는 대부분의 연구들 은 이명의 어려움을 중등도 이상으로 호소하는 대상자로 한정 하여 이명으로 인한 어려움은 있지만 그 정도가 경증에 해당하 는 대상자들의 소리치료 효과를 확인할 수는 없었다. 하지만 전 체 이명 대상자 중 경도에 속하는 대상자는 국가에 따라 다소 차 이는 있지만 약 $69 \%$ 이상으로 보고하고 있어 그 숫자가 적지 않 으며, 이 중 이명 재활을 원하는 대상자들을 위해 청각 전문가가 참고할 수 있는 소리치료 효과 연구 보고가 부재하다(Jin et al., 2021a; Jin et al., 2021b; McCormack et al., 2016; Tyler et al., 2020).

본 연구는 소리치료가 경도 이명 대상자들에게 유의미한 이 명 개선 효과를 제공하는지 확인하고자 하였다. 선행 연구들의 결과를 요약하면, 경도 이명 대상자들에게 소리치료가 유의미한 개선 효과가 나타날 수 있는지에 대한 정보가 제한적이다. 따라 서 본 연구는 이명 완화를 원하는 경도 이명 대상자만을 모집하 여 소리치료를 실시하였을 때 이명의 개선 효과가 나타날 수 있 는지 확인하고자 하였다.

\section{MATERIALS AND METHODS}

\section{연구 대상}

모든 연구 대상자들은 1년 이상 지속된 경도 이명을 갖고 있으 며, 이명으로 인한 불편함을 호소하는 대상자를 포함하였다. 또 한 소리치료 애플리케이션의 원활한 진행을 위해 스마트폰 사용 에 어려움이 없으며, 이명의 어려움 및 이명으로 인한 삶의 질 정 도를 측정하는 설문지인 한국어버전 이명주요기능설문지의 평 균 점수가 40 점 이하인 경도 이명을 보고한 대상자 중에서 3 개 월 동안 꾸준히 소리치료를 시행할 의지가 있는 대상자들을 포 함하였다. 이명주요기능설문지의 경우에는 점수 분포에 따른 이 명의 심각성 및 어려움 정도의 분류는 제안된 적이 없지만 이명 주요기능설문지 점수가 30 점 이하인 대상자들은 이명으로 인한 심각성 및 어려움 정도가 낮은 경도 이명으로 간주하거나(Tyler et al., 2020), 한국어버전 이명주요기능설문지 총점이 20 40점 사이일 경우 경도 수준의 이명으로 분류하여 분석한 바 있다(Jin et al., 2021b). 따라서 경도 이명으로 분석된 적이 있는 한국어 버전 이명주요기능설문지의 총점이 40점 이하인 경우를 경도 이 명으로 정하여 연구를 진행하였다. 그 외의 기준으로 이명과 관 련된 치료 및 재활을 받고 있거나 보청기를 착용 중인 대상자, 현 재 이과적 및 정신적인 질환을 겪고 있는 대상자, 이명 및 청각과 관련된 법적 소송 중인 대상자는 제외하였다.

포함 기준은 1) 1년 이상 이명이 지속된 대상자, 2) 이명으로 인한 불편함을 호소하는 대상자, 3) 스마트폰 사용에 어려움이 없는 대상자, 4) 한국어버전 이명주요기능설문지 평균 점수가 40점 이하인 경도 이명 대상자, 5) 3개월 동안 꾸준히 소리치료 를 시행할 의지가 있는 대상자이다.

제외 기준은 1) 이명과 관련된 치료 및 재활을 받고 있는 대상 자, 2) 보청기를 착용 중인 대상자, 3) 이과적 및 정신적인 질환을 않고 있는 대상자, 4) 이명 및 청각과 관련된 법적 소송 중에 있 는 대상자이다.

대상자는 모두 12명(남 8명, 여 4명)이며, 평균 연령 49.67세 (연령 범위: 만 23-83세, SD: 16.19)의 성인이었다. 대상자들 의 평균 이명 기간은 85.50 개월(SD: 102.59 ), 평균 이명 주파수 는 좌측 귀가 $4,575 \mathrm{~Hz}(\mathrm{SD}: 3,399)$, 우측 귀가 $5,821 \mathrm{~Hz}$ (SD: 2,925)였으며, 평균 이명 크기는 좌측 귀에서 $5.82 \mathrm{~dB}$ sensation level (SL) (SD: 6.76), 우측 귀에서 3.29 dB SL (SD: 1.60)이었다. 한국어버전 이명주요기능설문지의 총 점수의 평균은 24.42 점 (SD: 10.76), 시각아날로그척도(Visual Analogue Scale)의 크 기와 짜증 점수의 평균은 각각 47.08점(SD: 20.72), 49.17점(SD: 17.30)이었다(Table 1).

본 연구 대상자들의 순음청력검사 결과 평균을 Figure 1에 제 시하였다. 순음청력검사 결과, 우측 귀는 $250 ~ 2,000 ~ H z$ 에서는 
정상 청력을 보였으나 4,000 8,000 Hz까지 미도에서 경도로 하강하는 난청을 보였다. 좌측 귀는 $250 \sim 2,000 \mathrm{~Hz}$ 에서는 정상 청력을 보였으나 4,000 8,000 Hz까지 경도에서 중도로 하강하 는 난청을 나타냈다. 대상자들의 양이 청력 차이를 확인하기 위 해 주파수별로 독립표본 $t$-검정(independent $t$-test)을 실시한 결과, $250 \mathrm{~Hz}$ 에서 좌측 평균 $19.17 \mathrm{~dB} \mathrm{HL}$ (SD: 7.33), 우측 평 균 $15.42 \mathrm{~dB} \mathrm{HL}$ (SD: 9.40) ( $p=0.288), 500 \mathrm{~Hz}$ 에서 좌측 평 균 $14.58 \mathrm{~dB} \mathrm{HL}$ (SD: 4.50), 우측 평균 $13.33 \mathrm{~dB} \mathrm{HL}$ (SD: 8.07) ( $p=0.645), 1,000 \mathrm{~Hz}$ 에서 좌측 평균 $12.91 \mathrm{~dB} \mathrm{HL}$ (SD: 10.33), 우측 평균 $11.25 \mathrm{~dB} \mathrm{HL}(\mathrm{SD}: 9.08)(p=0.679), 2,000 \mathrm{~Hz}$ 에서 좌측 평균 $18.33 \mathrm{~dB} \mathrm{HL}$ (SD: 12.67), 우측 평균 $13.75 \mathrm{~dB} \mathrm{HL}$ (SD: 16.11) ( $p=0.447), 4,000 \mathrm{~Hz}$ 에서 좌측 평균 $32.92 \mathrm{~dB}$ $\mathrm{HL}$ (SD: 4.81), 우측 평균 $24.17 \mathrm{~dB} \mathrm{HL}$ (SD: 27.95) ( $p=0.426$ ), $8,000 \mathrm{~Hz}$ 에서 좌측 평균 $51.67 \mathrm{~dB} \mathrm{HL}$ (SD: 29.87), 우측 평균 $32.50 \mathrm{~dB} \mathrm{HL}$ (SD: 27.59) ( $p=0.117$ )로 모든 주파수 영역에서 양이 평균 청력 간 유의미한 차이는 나타나지 않았다.

\section{연구 절차}

본 연구는 인터넷 이명 커뮤니티(네이버 카페 고군분투, http://cafe.naver.com/onquest)에 설문지 형식의 모집 공고 를 통하여 연구 참여자를 모집하였다. 설문지 내용은 이명 기간, 치료 및 재활 여부, 난청 진단 및 이과적 치료 이력, 보청기 착용
여부, 현재 가지고 있는 이과적 질환에 관한 내용으로 이루어져 있었으며, 연구 참여 희망자들은 설문지를 작성하여 온라인으로 신청하였다. 설문지를 통해 총 50명이 지원하였고, 지원자를 대 상으로 전화 인터뷰를 통해 38 명이 탈락하여 12 명을 최종 연구 대상자로 선정하였다. 탈락한 대상자들은 보청기 착용(9명), 이 과적 및 정신적 질환(5명), 이명과 관련된 치료 및 재활(10명), 이 명 기간이 1년 미만(2명), 청력손실(12명)과 같은 사유로 연구에

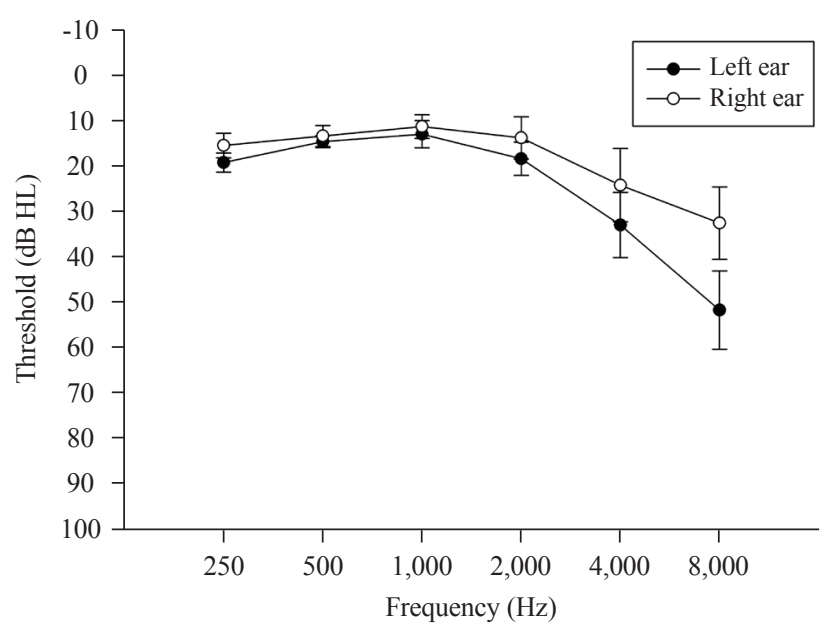

Figure 1. Results of the average puretone thresholds for all participants.

Table 1. Demographic data, characteristics of tinnitus, and baseline K-TPFQ scores in 12 participants

\begin{tabular}{|c|c|c|c|c|c|c|c|c|c|c|}
\hline \multirow{2}{*}{$\begin{array}{l}\text { Participants } \\
\text { No. }\end{array}$} & \multirow{2}{*}{$\begin{array}{c}\text { Age } \\
\text { (years) }\end{array}$} & \multirow[t]{2}{*}{ Gender } & \multirow{2}{*}{$\begin{array}{l}\text { Duration } \\
\text { of tinnitus } \\
\text { (months) }\end{array}$} & \multicolumn{2}{|c|}{$\begin{array}{l}\text { Tinnitus frequency } \\
(\mathrm{Hz})\end{array}$} & \multicolumn{2}{|c|}{$\begin{array}{l}\text { Tinnitus loudness } \\
\text { (dB SL) }\end{array}$} & \multirow{2}{*}{$\begin{array}{c}\text { Averaged } \\
\text { K-TPFQ } \\
\text { score, total }\end{array}$} & \multicolumn{2}{|c|}{$\begin{array}{c}\text { Averaged VAS score, } \\
\text { total }\end{array}$} \\
\hline & & & & Left & Right & Left & Right & & $\mathrm{L}$ & A \\
\hline 1 & 46 & M & 13 & 500 & - & 0 & - & 26.5 & 15 & 60 \\
\hline 2 & 55 & M & 24 & 8,000 & 8,000 & 2 & 2 & 31.0 & 60 & 60 \\
\hline 3 & 23 & $\mathrm{~F}$ & 24 & 6,000 & - & 1 & - & 12.5 & 30 & 30 \\
\hline 4 & 45 & $\mathrm{~F}$ & 48 & 4,000 & - & 6 & - & 6.5 & 60 & 20 \\
\hline 5 & 55 & M & 24 & - & 4,000 & - & 5 & 17.5 & 60 & 60 \\
\hline 6 & 43 & M & 14 & 8,000 & 8,000 & 1 & 2 & 37.5 & 60 & 60 \\
\hline 7 & 43 & M & 72 & 8,000 & 8,000 & 0 & 2 & 37.5 & 80 & 70 \\
\hline 8 & 35 & M & 194 & 8,000 & 8,000 & 17 & 5 & 31.0 & 60 & 60 \\
\hline 9 & 73 & $\mathrm{~F}$ & 120 & 1,000 & - & 15 & - & 15.0 & 40 & 50 \\
\hline 10 & 55 & M & 360 & - & 4,000 & 0 & 5 & 13.5 & 10 & 20 \\
\hline 11 & 83 & M & 108 & 250 & 750 & 15 & 2 & 31.0 & 40 & 40 \\
\hline 12 & 40 & $\mathrm{~F}$ & 25 & 2,000 & - & 7 & - & 34.0 & 60 & 60 \\
\hline Mean & 49.67 & - & 85.50 & 4,575 & 5,821 & 5.82 & 3.29 & 24.42 & 47.08 & 49.17 \\
\hline SD & 16.19 & - & 102.59 & 3,399 & 2,925 & 6.76 & 1.60 & 10.76 & 20.72 & 17.30 \\
\hline Range & $23 \sim 83$ & - & $13 \sim 360$ & $250 \sim 8,000$ & $750 \sim 8,000$ & $0 \sim 17$ & $2 \sim 5$ & $6.5 \sim 37.5$ & $10 \sim 80$ & $20 \sim 70$ \\
\hline
\end{tabular}

K-TPFQ: Korean version of the Tinnitus Primary Function Questionnaire, SL: sensation level, VAS: Visual Analogue Scale, L: loudness, A: anxiety, M: male, F: female, SD: standard deviation 
서 제외하였다.

본 연구의 포함 및 제외 기준에 의하여 선정된 12 명의 연구 대상자들은 초기 검사와 3 개월 후속 검사를 위해 실험실로 방 문하였고, 모든 대상자들에게 연구의 목적과 절차에 대한 설명 을 제공하였으며, 대상자들은 연구동의서에 자발적으로 서명하 였다. 또한, 본 연구는 연구자들이 소속된 기관의 임상실험윤리 위원회(Institutional Review Board, IRB)의 승인을 받아 진 행하였다(승인번호: \#HIRB-2020-069). 검사를 실시하기 전, 연구 참여자들은 상담실에서 한국어버전 이명주요기능설문지 와 시각아날로그척도를 작성하였다. 한국어버전 이명주요기능 설문지는 집중, 감정, 청각, 수면과 관련된 20 개의 문항으로 구 성되어 있으며, 대상자는 각 문항에 대하여 0점(전혀 아니다)에 서 100점(매우 그렇다)으로 평가한다. 이를 통해 대상자들이 주 로 어떤 영역에서 이명에 의해 고통을 느끼고 있는지 알 수 있다. 설문지 작성 후 순음청력검사(pure-tone audiometry)와 이 명도(tinnitogram)검사를 실시하였다. 이명도검사는 음조매칭 (pitch matching)검사와 음량매칭(loudness matching)검사 로 구성하였다. 검사는 방음실(double-walled sound booth)

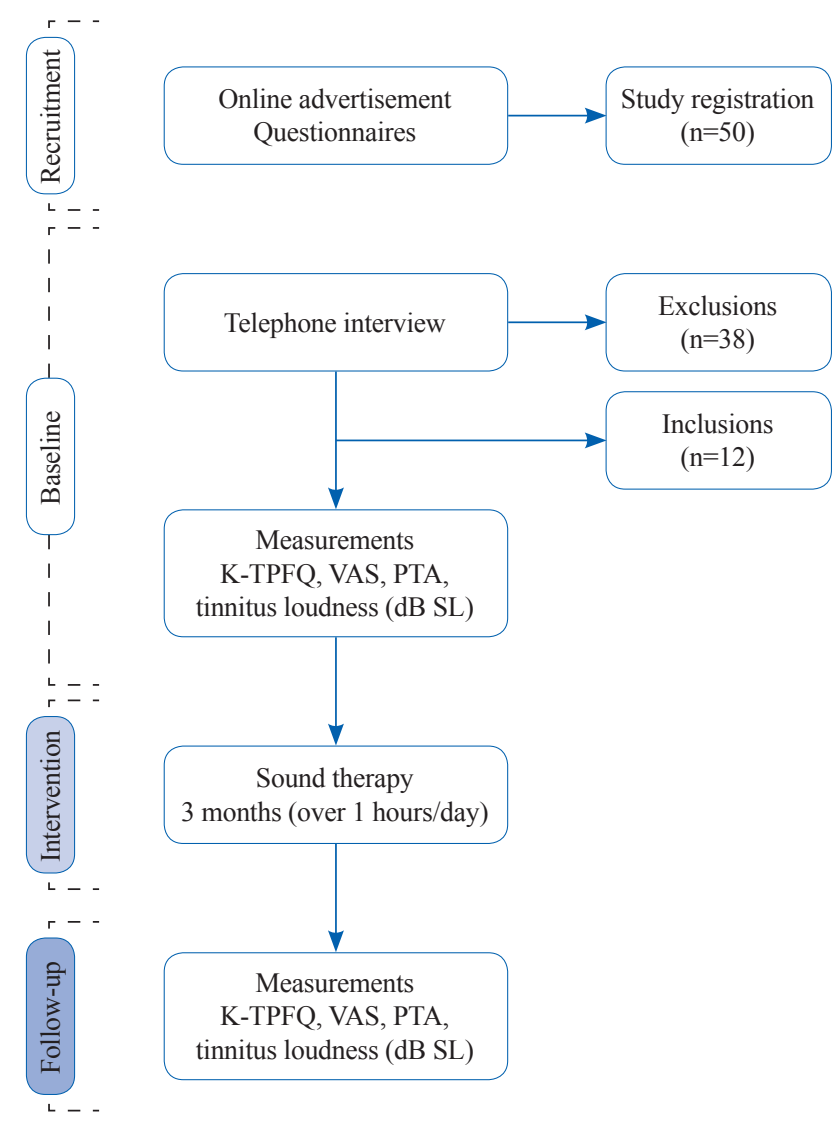

Figure 2. Schema of the protocol for the present study. K-TPFQ: Korean version of the Tinnitus Primary Function Questionnaire, VAS: Visual Analogue Scale, PTA: pure-tone audiometry, SL: sensation level.
에서 청력검사기(GSI-61; Grason-Stadler Inc., Eden Prairie, MN, USA)와 헤드폰(TDH-50; Teleponics Corporation, Farmingdale, NY, USA)을 사용하여 실시하였다. 또한 본 연 구는 경도 이명 대상자들의 소리치료 효과를 확인하기 위해 초 기 검사 시 이명 관련 상담을 제외한 소리치료 애플리케이션의 사용 방법에 대한 상담만을 진행하였고, 3 개월 후속 검사 시 이 명 관련 상담을 포함하여 진행하였다. 검사와 상담의 소요 시간 은 40 60분이었으며, 대상자들의 요구가 있을 때마다 충분한 휴식을 제공하였다. 또한 검사를 완료한 후 모든 대상자들에게 소정의 보상을 제공하였다.

대상자들은 3 개월 동안 주 5 회 이상의 소리치료를 최소 1 시 간 이상 시행하되, 대상자가 원하는 시간만큼 소리치료를 시행 하도록 권고하였고, 개방형 이어폰(ONE, MIJ, Chuncheon, Korea)을 제공하였다. 소리치료 진행 중 이명의 크기나 소리가 변하면 담당 연구원이 음원의 크기를 원격으로 조정하였다. 본 연구의 절차를 Figure 2에 제시하였다.

\section{소리치료 애플리케이션}

본 연구는 자체 개발한 휴대폰 소리치료 애플리케이션을 통해 진행하였다(Jin et al., 2021b). 애플리케이션은 대상자들이 편 안한 환경에서 소리치료를 진행할 수 있도록 개발하였다. 음원의 강도는 이명과 광대역잡음 $(100 ~ 22,050 \mathrm{~Hz})$ 이 동시에 들리는 혼합점(mixing point) (Jastreboff \& Jastreboff, 2000) 수준 으로 설정하였다. 소리치료에 사용된 광대역잡음의 스펙트럼을 Figure 3에 제시하였다. 일반적으로, 휴대폰의 볼륨은 15 20단 계로 이루어져 있지만, 본 애플리케이션은 휴대폰의 볼륨을 100 단 계로 나누어 강도를 조절할 수 있기 때문에 혼합점에 가깝게 음 원 강도를 설계하였다. 애플리케이션은 대상자들이 음원의 강도

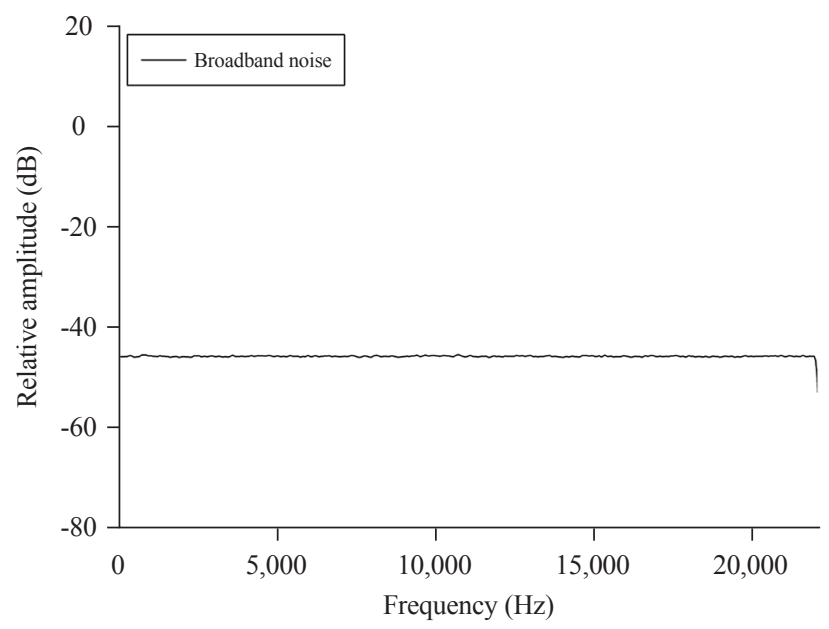

Figure 3. Spectrum analysis of broadband noise as the function frequency. 
와 종류를 임의로 변경할 수 없도록 설계하였고 구동 화면에서 음원의 재생 및 중지 기능만을 사용할 수 있었으며, 홈 화면에서 는 소리치료 진행 시간을 실시간으로 확인하고 이명의 방향, 주 파수 및 크기와 같은 이명 상태를 확인할 수 있도록 설계하였다. 또한 통계 화면에서는 대상자들이 얼마나 소리치료를 진행했는 지 날짜별로 검색하여 확인이 가능하도록 구성하였고, 설정 화 면에서는 타이머를 설정할 수 있도록 하여 원하는 시간만큼만 재생할 수 있도록 설계하였다. 음원 재생 중에 전화를 받는 경우 에는 자동으로 음원이 중지되고 통화 종료 후 다시 재생되도록
설계하였다. 또한 데이터 로깅 기능을 통해 연구원들은 대상자 들의 실제 애플리케이션 사용 시간을 추적할 수 있도록 설계하 여 소리치료를 평일 오후 8 시까지 일일 최소 수행 시간인 1시간 을 시행하지 않은 대상자에게는 전화 및 메시지를 통해 최소 1시 간 이상 소리치료를 수행하도록 재안내하였다.

\section{통계 분석}

본 연구는 3개월 동안 진행된 소리치료 전후의 한국어버 전 이명주요기능설문지, 시각아날로그척도 점수 및 이명 크기

Table 2. Averaged K-TPFQ and VAS scores for loudness and anxiety, and tinnitus loudness at baseline and 3-month

\begin{tabular}{|c|c|c|c|c|c|c|c|c|c|c|}
\hline & \multicolumn{2}{|c|}{$\begin{array}{l}\text { Averaged K-TPFQ } \\
\text { score, total }\end{array}$} & \multicolumn{2}{|c|}{$\begin{array}{c}\text { Averaged VAS score, } \\
\text { loudness }\end{array}$} & \multicolumn{2}{|c|}{$\begin{array}{l}\text { Averaged VAS score, } \\
\text { anxiety }\end{array}$} & \multicolumn{4}{|c|}{ Averaged tinnitus loudness (dB SL) } \\
\hline & \multirow{2}{*}{ Baseline } & \multirow{2}{*}{ 3-month } & \multirow{2}{*}{ Baseline } & \multirow{2}{*}{ 3-month } & \multirow{2}{*}{ Baseline } & \multirow{2}{*}{ 3-month } & \multicolumn{2}{|c|}{ Baseline } & \multicolumn{2}{|c|}{ 3-month } \\
\hline & & & & & & & $\mathrm{L}$ & $\mathrm{R}$ & $\mathrm{L}$ & $\mathrm{R}$ \\
\hline Score & 24.42 & 23.67 & 47.08 & 47.08 & 49.17 & 43.33 & 5.82 & 3.29 & 4.18 & 3.00 \\
\hline $\mathrm{SD}$ & 10.76 & 15.77 & 20.72 & 22.81 & 17.30 & 21.88 & 6.76 & 1.60 & 3.31 & 3.32 \\
\hline SE & 3.11 & 4.55 & 5.98 & 6.58 & 4.99 & 6.32 & 2.04 & 1.00 & 1.00 & 1.25 \\
\hline
\end{tabular}

K-TPFQ: Korean version of the Tinnitus Primary Function Questionnaire, VAS: Visual Analogue Scale, SL: sensation level, L: left ear, R: right ear, SD: standard deviation, SE: standard error

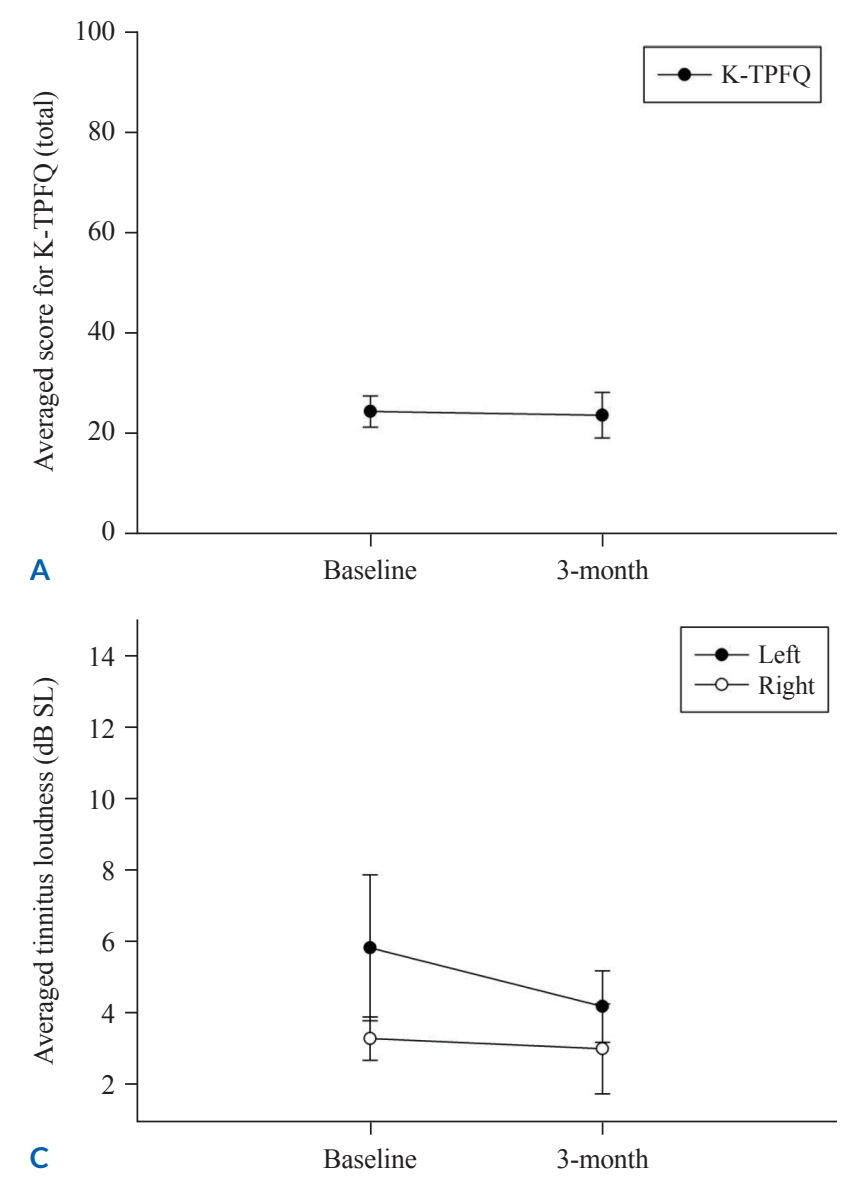

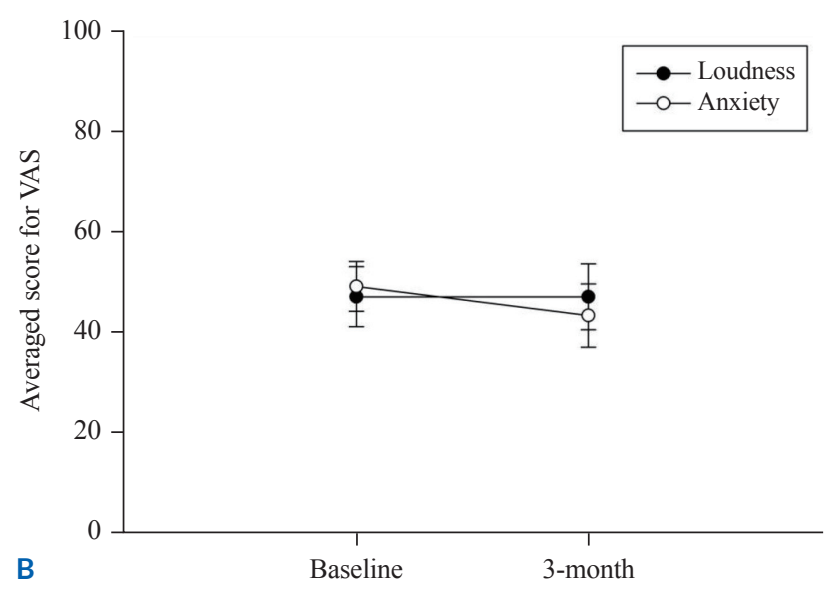

Figure 4. Averaged K-TPFQ (A) and VAS scores for loudness and anxiety (B), and Tinnitus loudness (C) at baseline and 3-month. K-TPFQ: Korean version of the Tinnitus Primary Function Questionnaire, VAS: Visual Analogue Scale, SL: sensation level. 
를 비교하기 위해 통계 소프트웨어 SPSS (ver. 25; IBM Corp., Armonk, NY, USA)를 사용하여 대응표본 $t$-검정(paired $t$-test)을 실시하였다.

\section{RESULTS}

본 연구는 경도 이명 대상자들이 3개월간 소리치료 애플리케 이션을 사용하여 소리치료를 진행하고, 소리치료 전후에 작성한 한국어버전 이명주요기능설문지와 시각아날로그척도의 점수 및 이명 크기를 비교하였다(Table 2, Figure 4). 한국어버전 이명 주요기능설문지의 평균 점수는 24.42점(SD: 10.76)에서 23.67점 (SD: 15.77)으로 평균 0.75점 감소하였으며, 이는 통계적으로 유 의미하지 않은 차이를 나타냈다 $(p=0.828)$. 시각아날로그척 도의 크기 점수에서는 평균 47.08점(SD: 20.72)에서 47.08점 (SD: 22.81)으로 변화가 없었고( $p=1.000)$, 짜증 점수에서는 49.17점(SD: 17.30)에서 43.33점(SD: 21.88)으로 5.84점 감소 하였으며 $(p=0.223)$ 이는 통계적으로 유의미하지 않았다. 이명 크기의 경우, 좌측은 평균 $5.82 \mathrm{~dB} \mathrm{SL}$ (SD: 6.76)에서 $4.18 \mathrm{~dB}$ $\mathrm{SL}$ (SD: 3.31)로 $1.64 \mathrm{~dB}$ 만큼 감소하였으나 유의미하지 않았 으며( $p=0.527)$, 우측은 평균 $3.29 \mathrm{~dB} \mathrm{SL}$ (SD: 1.60)에서 3.00 $\mathrm{dB}$ SL (SD: 3.32)로 $0.29 \mathrm{~dB}$ 만큼 감소하였으나 통계적으로 유 의미하지 않았다 $(p=0.838)$.

\section{DISCUSSIONS}

본 연구는 경도 이명을 가진 대상자들을 모집하여 소리치료를 실시하였을 때 이명의 개선 효과가 나타나는지 확인해보고자 하 였다. 12 명의 대상자들은 휴대폰 애플리케이션을 통해 소리치료 를 진행하였다. 음원은 광대역잡음을 사용하였으며, 일일 최소 1 시간 이상 3 개월 동안 소리치료를 시행하도록 안내하였다. 소리 치료 전후의 효과는 한국어버전 이명주요기능설문지와 시각아 날로그척도의 점수 및 이명 크기를 비교하여 확인하였다. 연구 결과, 한국어버전 이명주요기능설문지는 평균 0.75 점이 감소하 였고, 시각아날로그척도의 크기와 짜증 점수는 각각 평균 0.0점, 5.84 점이 감소하였으며, 이명 크기는 좌측 평균 $1.64 \mathrm{~dB}$, 우측 평균 $0.29 \mathrm{~dB}$ 만큼 감소하였으나 모두 통계적으로 유의미하지 않았다.

소리치료 전후 대상자들의 한국어버전 이명주요기능설문지, 시각아날로그척도 및 이명 크기에 대한 개인별 점수를 Table 3 에 제시하였다. Tyler et al.(2020)은 이명주요기능설문지의 점 수가 13점 이상 감소하였을 때 유의미한 개선으로 판단할 수 있 다고 보고하였다. 본 연구의 한국어버전 이명주요기능설문지에 서 13점 이상 유의미한 개선을 보인 대상자는 1 명이었지만, 10점 이상의 개선을 보인 대상자는 총 3 명이었다. 감소의 원인은 다양 할 수 있지만, 일일 소리치료 사용 시간이 평균 4.8시간으로 다 른 대상자들에 비해서 길었던 점이 효과를 보였을 수 있다.

본 연구에서 경도 이명의 대상자들에게 소리치료만을 제공 하였을 때, 대부분의 대상자에게서 유의미한 개선 효과가 나타

Table 3. Individual K-TPFQ and VAS scores for loudness and anxiety, and tinnitus loudness at baseline and 3 months

\begin{tabular}{|c|c|c|c|c|c|c|c|c|c|c|c|c|c|c|c|}
\hline \multirow{3}{*}{$\begin{array}{l}\text { Participants } \\
\text { No. }\end{array}$} & \multicolumn{3}{|c|}{ K-TPFQ score } & \multicolumn{3}{|c|}{ VAS for loudness score } & \multicolumn{3}{|c|}{ VAS for anxiety score } & \multicolumn{6}{|c|}{ Tinnitus loudness (dB SL) } \\
\hline & \multirow{2}{*}{ Base } & \multirow{2}{*}{$3 \mathrm{mo}$} & \multirow{2}{*}{$\operatorname{Imp}$} & \multirow{2}{*}{ Base } & \multirow{2}{*}{$3 \mathrm{mo}$} & \multirow{2}{*}{ Imp } & \multirow{2}{*}{ Base } & \multirow{2}{*}{$3 \mathrm{mo}$} & \multirow{2}{*}{$\operatorname{Imp}$} & \multicolumn{2}{|c|}{ Base } & \multicolumn{2}{|c|}{$3 \mathrm{mo}$} & \multicolumn{2}{|c|}{$\operatorname{Imp}$} \\
\hline & & & & & & & & & & $\mathrm{L}$ & $\mathrm{R}$ & $\mathrm{L}$ & $\mathrm{R}$ & $\mathrm{L}$ & $\mathrm{R}$ \\
\hline 1 & 26.5 & 14.0 & 12.5 & 15 & 10 & 5 & 60 & 70 & -10 & 0 & - & 6 & - & -6 & - \\
\hline 2 & 31.0 & 20.0 & 11.0 & 60 & 60 & 0 & 60 & 40 & 20 & 2 & 2 & 1 & 0 & 1 & 2 \\
\hline 3 & 12.5 & 3.0 & 9.5 & 30 & 15 & 15 & 30 & 10 & 20 & 1 & - & 1 & - & 0 & - \\
\hline 4 & 6.5 & 15.0 & -8.5 & 60 & 40 & 20 & 20 & 20 & 0 & 6 & - & 6 & - & 0 & - \\
\hline 5 & 17.5 & 42.0 & -24.5 & 60 & 50 & 10 & 60 & 70 & -10 & - & 5 & - & 6 & - & -1 \\
\hline 6 & 37.5 & 43.0 & -5.5 & 60 & 60 & 0 & 60 & 60 & 0 & 1 & 2 & 9 & 9 & -8 & -7 \\
\hline 7 & 37.0 & 46.5 & -9.5 & 80 & 60 & 20 & 70 & 50 & 20 & 0 & 2 & 3 & 1 & -3 & 1 \\
\hline 8 & 31.0 & 26.5 & 4.5 & 60 & 60 & 0 & 60 & 60 & 0 & 17 & 5 & 0 & 3 & 17 & 2 \\
\hline 9 & 15.0 & 0.0 & 15.0 & 40 & 10 & 30 & 50 & 10 & 40 & 15 & - & 7 & - & 8 & - \\
\hline 10 & 13.5 & 13.5 & 0.0 & 10 & 70 & -60 & 20 & 30 & -10 & 0 & 5 & 5 & 1 & -5 & 4 \\
\hline 11 & 31.0 & 22.0 & 9.0 & 40 & 60 & -20 & 40 & 40 & 0 & 15 & 2 & 0 & 1 & 15 & 1 \\
\hline 12 & 34.0 & 38.5 & -4.5 & 50 & 70 & -20 & 60 & 60 & 0 & 7 & - & 8 & - & -1 & - \\
\hline
\end{tabular}

K-TPFQ: Korean version of the Tinnitus Primary Function Questionnaire, VAS: Visual Analogue Scale, SL: sensation level, Base: baseline, mo: months, Imp: improvement, L: left ear, R: right ear 
나지 않았다. 이는 경도 이명 대상자에게 있어 소리치료만으로 는 충분한 효과를 기대하기 어렵다는 것을 의미한다. Henry et al.(2006)은 '중도'의 이명 대상자들을 임상의의 필요에 의해 상 담을 진행한 이명차폐 그룹과 신경생리학적 모델에 기반한 구조 화된 상담이 포함된 이명재훈련치료 그룹으로 나누어 효과 크기 를 비교하였다. 연구 결과, 이명차폐 그룹의 효과 크기는 0.35 , 이 명재훈련치료 그룹의 효과 크기는 0.49 로 이명재훈련치료 그룹 에서 더 높게 나타났다. 따라서 상담을 동반한 소리치료가 경도 이명 대상자에게 더 좋은 효과를 나타낼 수 있는 가능성이 있음 을 시사한다. 따라서 경도 이명 대상자의 경우, 상담과 같은 추가 적인 재활법을 소리치료와 동반하는 접근법을 고려할 수 있다.

본 연구에는 몇 가지 한계점이 있다. 연구에 참여한 대상자 가 12 명으로 적었기 때문에 경도 이명 대상자의 소리치료 효과 를 더욱 명확히 확인하기 위해서는 더 많은 그룹 대상자가 필요 하다. 다음으로 연구원들의 권고에 따라 대상자들은 1 시간 이상 소리치료를 진행했지만 개인별 사용 시간은 모두 달랐다. 따라서 향후 연구에서는 시간에 따른 경도 이명 대상자의 중재 효과에 대한 연구가 필요하다. 또한 본 연구는 3개월 동안의 소리치료 효과를 관찰한 연구로, 12 18개월 동안 시행한 선행 연구와 비 교하였을 때(Bauer \& Brozoski, 2011; Tyler et al., 2012) 다 소 단기간 진행하였다. 향후 연구에서는 경도 이명 그룹을 대상 으로 장기간 소리치료를 진행한 재활 전후의 효과를 비교한 연 구가 필요하다.

본 연구는 3 개월 동안 경도 이명 대상자들의 소리치료 효과를 확인하였다. 그 결과 한국어버전 이명주요기능설문지, 시각아날 로그척도 점수 및 이명 크기 모두 유의미한 감소가 나타나지 않 았다. 본 연구의 결과는 경도 이명 대상자의 경우 소리치료만으 로는 유의미한 개선 효과를 기대하기 어렵다는 것을 보여주었다. 따라서 경도 이명 대상자들의 효과적인 이명 재활을 위한 후속 연구가 요구되며, 청각 전문가들은 경도 이명 대상자의 이명 재 활을 계획할 때 소리치료만을 고려하는 것은 주의할 필요가 있 다.

중심 단어: 소리치료, 이명, 경도 이명, 소리치료 애플리케이션.

\section{Ethical Statement}

The study was approved by the Institutional Review Board of Hallym University (HIRB-2020-069).

\section{Acknowledgments}

N/A

\section{Declaration of Conflicting Interests}

There are no conflict of interests.

\section{Funding}

This work was supported by the National Research Foundation of Korea grant funded by the Korean government (Ministry of Science and ICT; Grant NRF-2018R1C1B6003765).

\section{Author Contributions}

Conceptualization: In-Ki Jin. Data curation: All authors. Funding acquisition: In-Ki Jin. Investigation: YeonWoo Sim, TaeRim Lee. Project administration: YeonWoo Sim, In-Ki Jin. Validation: All authors. Writing_-original draft: All authors. Writing - review \& editing: YeonWoo Sim, In-Ki Jin. Approval of final manuscript: All authors.

\section{ORCID ID}

YeonWoo Sim https://orcid.org/0000-0002-7663-5614

TaeRim Lee

In-Ki Jin https://orcid.org/0000-0002-4115-7712 https://orcid.org/0000-0002-0834-5981

\section{REFERENCES}

Andersson, G. (2002). Psychological aspects of tinnitus and the application of cognitive-behavioral therapy. Clinical Psychology Review, 22(7), 977-990.

Bauer, C. A. \& Brozoski, T. J. (2011). Effect of tinnitus retraining therapy on the loudness and annoyance of tinnitus: a controlled trial. Ear and Hearing, 32(2), 145-155.

Cohen, J. (2013). Statistical Power Analysis for the Behavioral Sciences. (2nd ed.), (pp.1-490). New York, NY: Academic Press.

Heller, A. J. (2003). Classification and epidemiology of tinnitus. Otolaryngologic Clinics of North America, 36(2), 239-248.

Henry, J. A., Schechter, M. A., Zaugg, T. L., Griest, S., Jastreboff, P. J., Vernon, J. A., et al. (2006). Clinical trial to compare tinnitus masking and tinnitus retraining therapy. Acta Oto-laryngologica Supplementum, (556), 64-69.

Jastreboff, P. J. \& Jastreboff, M. M. (2000). Tinnitus retraining therapy (TRT) as a method for treatment of tinnitus and hyperacusis patients. Journal of the American Academy of Audiology, 11(3), 162177.

Jastreboff, P. J. (1990). Phantom auditory perception (tinnitus): mechanisms of generation and perception. Neuroscience Research, 8(4), 221-254.

Jin, I. K., Choi, S. J., \& Ku, M. (2021a). Notched and nonnotched stimuli are equally effective at the mixing-point level in sound therapy for tinnitus relief. Journal of the American Academy of Audiology, 32(7), 420-425.

Jin, I. K., Choi, S. J., Yoo, J., Jeong, S., Heo, S., \& Oh, H. (2021b). Effects of tinnitus sound therapy determined using subjective measurements. 
Journal of the American Academy of Audiology, 32(4), 212-218.

McCormack, A., Edmondson-Jones, M., Somerset, S., \& Hall, D. (2016). A systematic review of the reporting of tinnitus prevalence and severity. Hearing Research, 337, 70-79.

Shin, J., Heo, S., Lee, H. K., Tyler, R., \& Jin, I. K. (2019). Reliability and validity of a Korean version of the tinnitus primary function questionnaire. American Journal of Audiology, 28(2), 362-368.

Tyler, R., Ji, H., Perreau, A., Witt, S., Noble, W., \& Coelho, C. (2014). Development and validation of the tinnitus primary function questionnaire. American Journal of Audiology, 23(3), 260-272.
Tyler, R. S. (2006). Tinnitus Treatment: Clinical Protocols. In Tyler, R. S. (1st ed.). Neurophysiological Models, Psychological Models, and Treatments for Tinnitus (pp.1-22). New York, NY: Thieme.

Tyler, R. S., Noble, W., Coelho, C. B., \& Ji, H. (2012). Tinnitus retraining therapy: mixing point and total masking are equally effective. Ear and Hearing, 33(5), 588-594.

Tyler, R. S., Perreau, A., Powers, T., Watts, A., Owen, R., Ji, H., et al. (2020). Tinnitus sound therapy trial shows effectiveness for those with tinnitus. Journal of the American Academy of Audiology, 31(1), 6-16. 